\title{
Optimizing Clinical Diagnosis and Antibiotic Prescribing for Common Respiratory Tract Infections, Fanara Family Health Center- Rural Egypt
}

\author{
${ }^{1}$ Sameh F. Ahmed, ${ }^{1}$ Enayat M. Soltan, \\ ${ }^{1}$ Department of Family Medicine, Faculty of Medicine, Suez Canal University, Egypt
}

\begin{abstract}
Background: Antibiotic prescribing for respiratory tract infections (RTI) by primary care doctors has received renewed interest due to the continuing emergence of antibiotic resistance, increased incidence of adverse effects and the attendant cost to healthcare especially in developing countries like Egypt. Despite the majority of these infections being viral it seems that many determinants other than the etiology are the main factors that influence a high rate of prescribing antibiotic for these self-limiting infections. Objective: We aimed to assess the impact of a physician- based educational intervention to improve clinical diagnosis of bacterial causes of RTIs and reduce unnecessary antibiotic prescription for these infections. Methods: This is a clinical trial, where 11 family medicine residents working at a rural family health center in Egypt participated in an educational program to improve their antibiotic prescribing skills when treating common RTI. Their patterns of prescribing antibiotic have been studied among all patients 3 months old or above who attended the family center with RTI, for 2 months before and after the educational intervention ( $1^{\text {st }}$ of December 2015 to $10^{\text {th }}$ of March 2016). The educational intervention comprised 4 hours, 2 lectures and another 4 hours, 2 small group discussions in updated management of RTI and health education principles based mainly on NICE guidelines and Health Belief Model (HBM) respectively. The primary outcome was measuring the impact of the educational intervention on rates of prescribing antibiotic for 4 RTI [Acute otitis media (AOM), tonsillopharyngitis, rhino sinusitis and acute bronchitis], the appropriateness of using clinical diagnostic criteria of bacterial causes of these infections and the appropriate selection of antibiotic when its use was justified. Results: The overall antibiotic prescription was significantly reduced $(8.3 \%)$ from base line $(80.3 \%)$ to post intervention $(72 \%)$ period, $(\mathrm{P}=0.007)$. This reduction was significant for both tonsillopharyngitis $(12.2 \%, \mathrm{P}=0.019)$ and otitis media $(14.2 \%, \mathrm{P}=0.033)$. There were also significant improvement in using clinical diagnostic criteria for bacterial causes of the four studied RTI with $12.5 \%$ overall improvement $(\mathrm{P}=0.001)$. There was also improvement in the overall appropriateness of selecting first line antibiotic when its use was justified this improvement was achieved for both tonsillopharyngitis $(17.8 \%, \mathrm{P}=$ $0.004)$ and $\mathrm{AOM}(\mathrm{P}=<0.001)$. Conclusion: Clinical diagnosis of bacterial causes of common RTIs and appropriate antibiotic use for these infections can be improved in primary health care settings using a physician based educational program.
\end{abstract}

Keywords: antibiotic, acute respiratory tract infections, health education, health belief model, proper prescribing

Correspondence author: Sameh F. Ahmed. Email: sfmahdi@moh.gov.sa

\section{INTRODUCTION:}

Respiratory tract infection (RTI) is defined as any infectious disease of the upper or lower respiratory tract. Upper respiratory tract infections (RTIs) include 
the common cold, laryngitis, pharyngitis/tonsillitis, acute rhinitis, acute rhino sinusitis and acute otitis media. Lower respiratory tract infections (LRTIs) include acute bronchitis, bronchiolitis, pneumonia and tracheitis. Although most RTIs are caused by viruses, antibiotics are commonly prescribed for these self-limiting conditions in adults and children in primary care.

Antibiotics transformed medical practice in the last half of the 20th century. Penicillin was even called a miracle drug by many in the 1950 s and 1960 s. Since that time, however, there has been increasing awareness that treating nonbacterial illnesses or those that are selflimiting with antibiotics contributes to the development of antibiotic-resistant bacteria. Reducing inappropriate antibiotic use is critical to slowing the progression of these resistant bacteria. Furthermore, inappropriate antibiotic use exposes patients unnecessarily to potential side effects associated with antibiotics and increases medical costs. ${ }^{1,2}$ A 2013 report of healthy adults visiting outpatient offices and emergency departments for acute RTIs revealed prescriptions for antibiotics were given at 73 percent of visits between 1996 and $2010,{ }^{3}$ despite the fact that the majority of acute RTIs cases are caused by viral pathogens for which antibiotics are not helpful. Therefore strategies that can help bring antibiotic use for RTIs in line with current evidence-based guidelines are clearly needed.

Three different antibiotic management strategies can be used for patients with RTI: no antibiotic prescribing; delayed antibiotic prescribing (in which an antibiotic prescription is written for use at a later date should symptoms worsen); and immediate antibiotic prescribing. A 2008 guideline by the United Kingdom's National Institute for Health and Clinical Excellence (NICE) ${ }^{4}$ entitled "Respiratory tract infections- antibiotic prescribing," recommended delayed or no antibiotic prescribing and patient education about the expected duration of RTI symptoms are the most appropriate strategies for treating acute RTIs. Perceived advantages of delayed prescribing as a strategy over no prescribing are that it offers a 'safety net' for the small proportion of patients who develop a complication, and that a patient expecting antibiotics may be more likely to agree with this course of action rather than with no prescribing. Delayed prescribing has therefore been advocated as an important management strategy to reduce inappropriate antibiotic prescribing. 5

\section{METHODS:}

The present study examined the antibiotic prescription patterns of 11 resident family physicians working in a rural university family health center in Egypt. The study included all patients 3 months old or above who attended the family center with acute tonsillopharyngitis, AOM, acute rhino sinusitis and bronchitis for 2 months before and after a physician based educational intervention ( $1{ }^{\text {st }}$ of December 2015 to $10^{\text {th }}$ of March 2016). Patients with chronic illnesses like diabetes and chronic renal failure, immune compromised patients and patients with penicillin allergy were excluded.

The educational intervention only comprised 4 hours, 2 lectures and another 4 hours 2 small group discussions in updated management of RTI based on NICE guidelines ${ }^{5}$ and health education principles based mainly on Health Belief Model (HBM). ${ }^{6}$ The lectures were conducted by a consultant family physician, and a written summary of the recommendations was distributed to participating physicians. Special emphasis was placed on improving diagnostic criteria for the four common RTI, improving criteria for immediate or delayed antibiotic prescription and make selection of antibiotic more appropriate 
when its use was justified as follows:

A. Improving diagnostic criteria: (1) AOM: Clinical criteria that assist in the diagnosis of acute otitis media include the abrupt onset of signs and symptoms, the presence of middle ear effusion that is indicated by any of the following: bulging of the tympanic membrane, limited or absent mobility of tympanic membrane, air fluid level behind the tympanic membrane, otorrhea, and signs or symptoms of middle ear inflammation as indicated by distinct erythema of the tympanic membrane or distinct otalgia (discomfort clearly referable to the ear[s] that interferes with or precludes normal activity or sleep). In a nonverbal child, ear holding, tugging, or rubbing suggests ear pain. ${ }^{7}$ (2) Acute tonsillopharyngitis: Patients who have Fever, PAIN score (fever $>38^{\circ} \mathrm{C}$, purulent tonsils, severe tonsil inflammation, absence of cough or coryza, symptoms onse $\leq 3$ days) of 2 or more may be more likely to benefit from an antibiotic. ${ }^{8}$ (3) Acute rhinosinusitis: A diagnosis of acute bacterial rhino sinusitis should be considered in patients with symptoms of a viral upper respiratory infection that have not improved after 10 days or that worsen after five to seven days. ${ }^{4}$ (4) Acute bronchitis: Cough that brings up clear, yellow, or green mucus is the most common presenting symptom and might be associated with sore throat, fever, chest congestion, shortness of breath, wheezing and body aches. ${ }^{9}$

B. Improving criteria for immediate or delayed antibiotic prescription: AOM: Antibiotics for AOM are effective only in reducing duration of pain in children aged between 6 months and 15 years and children who take antibiotics are more at risk of having adverse events. However, despite possible adverse reactions, antibiotics seem to be beneficial in children younger than 2 years with bilateral AOM and in children with both AOM and otorrhoea. ${ }^{4}$ Acute tonsillopharyngitis: For acute tonsillopharyngitis, a delayed and no prescribing strategies showed no significant differences in managing symptom duration or resolution compared with an immediate prescribing strategy. An immediate prescribing strategy may be considered cost effective for patients with a high baseline risk of quinsy and when three or more Fever Pain criteria are present. $^{8}$ Acute rhinosinusitis: For Acute rhinorhinosinusitis, the treatment should be the same way as the other four types of RTI, that is a delayed or a no antibiotic prescribing strategy should be offered to patients with acute rhinorhino sinusitiswho are not at increased risk of developing complications. ${ }^{4}$ Acute bronchitis: For acute bronchitis, there are no significant differences in managing symptom duration/severity between a delayed and no antibiotic prescribing strategies compared with an immediate prescribing strategy. ${ }^{4}$

C. Immediate antibiotic prescription strategy should be considered for any of RTI as follows: ${ }^{4}$ (i) If the patient is systemically very unwell. (ii) If the patient has symptoms and signs suggestive of serious illness and/or complications (particularly pneumonia, mastoiditis, peritonsillar abscess, peritonsillar cellulitis, intraorbital and intracranial complications). (iii) If the patient is at high risk of serious complications because of pre-existing comorbidity. This includes patients with significant heart, lung, renal, liver or neuromuscular disease, immunosuppression, cystic fibrosis, and young children who were born prematurely. (iv) If the patient is older than 65 years with acute cough and two or more of the following criteria, or older than 80 years with acute cough and one or more of the following criteria: Hospitalization in previous year, Type 1 or type 2 diabetes, current use of oral glucocorticoids. 
1. Improving selection of first line antibiotic when its use is justified: AOM: Amoxicillin is the antibiotic of choice unless the child received it within the previous 30 days, has concurrent purulent conjunctivitis, or is allergic to penicillin; in these cases, clinicians should prescribe an antibiotic with additional $\beta$-lactamase coverage. ${ }^{4}$

2. Acute tonsillopharyngitis: first choice antibiotic is penicillin $\mathrm{V}$ or amoxicillin. Alternative first choices for penicillin allergy or if penicillin is not tolerated are clarithromycin or erythromycin if pregnant. ${ }^{8}$

3. Acute rhinosinusitis: penicillin $\mathrm{V}$, amoxicillin or co-amoxiclav are first line treatment. Alternative first choices for penicillin allergy or intolerance include clarithromycin or erythromycin in pregnant women. ${ }^{9}$

4. Acute bronchitis: Amoxicillin is the antibiotic of choice unless the child received it within the previous 30 days, has concurrent purulent conjunctivitis, or is allergic to penicillin; in these cases, clinicians should prescribe an antibiotic with additional $\beta$-lactamase coverage. ${ }^{10}$

\section{Health education messages}

For all antibiotic prescribing strategies, patients should be given advice about the usual natural history of the illness, including the average total length of the illness: acute otitis media (4 days), acute tonsillopharyngitis (1 week), common cold (11/2 weeks) and acute rhino sinusitis ( $2 \frac{1}{2}$ weeks) acute bronchitis (3 weeks). When the no antibiotic prescribing strategy is adopted, patients should be offered reassurance that antibiotics are not needed immediately, a clinical review if the condition worsens or becomes prolonged. Start using the delayed prescription if symptoms are not starting to settle in accordance with the expected course of the illness or if a significant worsening of symptoms occurs. $^{4}$

Data retrieval: Data for every visit made during the pre- and post-intervention periods that met the inclusion criteria were retrieved from patient's file. Data included the attending physician, sociodemographic data of the patient, clinical diagnosis, the recorded criteria for diagnosis of RTI and the prescribed antibiotic.

Statistical analysis: Data were analyzed using Statistical Program for Social Science (SPSS) version 20.0. Quantitative data were expressed as mean \pm standard deviation (SD). Qualitative data were expressed as frequency and percentage. The following tests were done: Independent-samples ttest of significance was used when comparing between two means. Chisquare $\left(\mathrm{X}^{2}\right)$ test of significance was used in order to compare proportions between two qualitative parameters. The confidence interval was set to $95 \%$ and the margin of error accepted was set to $5 \%$. So, the p-value was considered significant as the following: $\mathrm{P}$-value $<0.05$ was considered significant, $\mathrm{P}$ value $<0.001$ was considered as highly significant and P-value >0.05 was considered insignificant.

\section{Results:}

Of the 400 visits for RTI by patients aged 6 months to 45 years during the preintervention period, 370 were eligible for analysis according to the study criteria. Of the 501 visits for RTI in the postintervention period, 475 were eligible for analysis.

Table 1: $\quad$ Socio-demographic characteristics. There was no statistical difference between two groups as regards to age, gender and duration of the RTI at the time of consultation.

Table 2: Frequency of diagnosis of RTI before and after intervention. There were no statistical difference in frequency of diagnosing all types of RTIs before and after intervention

Table 3: Rate of antibiotic prescription before and after intervention. There was a significant overall improvement $(8.3 \%$, $\mathrm{P}=0.007)$ in frequency of antibiotic 
prescription for RTI with subsequent improvement for both tonsillopharyngitis (12.2\%, $\mathrm{P}=0.019)$ and otitis media $(14.2 \%, \mathrm{P}=0.033)$.

Table 4: Changes in appropriateness of using diagnostic criteria for RTI before and after intervention. There was a significant overall improvement $(12.5 \%$, $\mathrm{P}=0.001$ ) in using clinical diagnostic criteria of bacterial causes of RTIs. Subsequently the improvement included tonsillopharyngitis $\quad(17.5 \% \quad \mathrm{P}=0.003)$, AOM $(17.1 \%, P=0.042)$, Acute rhino sinusitis $(\mathrm{P}=0.047)$ and acute bronchitis (16.7\%, $\mathrm{P}=0.032$ )

Table 5: Changes in appropriate selection of antibiotic during the two study periods. There was an overall improvement in using first line antibiotic when its use was justified $(\mathrm{P}<0.001)$ with subsequent improvement in selecting antibiotic for both tonsillopharyngitis (17.8\%, $\mathrm{P}=0.004)$ and AOM $(8.2 \%$, $8=0.004)$

\section{Discussion:}

This study is claimed to provide a clinical example of effectiveness of a physician based educational program in improving the quality and quantity of antibiotic prescription for common acute RTI including AOM, tonsillopharyngitis, rhino sinusitisand bronchitis. Several researchers have attempted to reduce antibiotic prescribing for respiratory tract infections by an educational intervention. (11-15) Most of them assessed overall antibiotic use for respiratory tract infections, and reported a drop in overall prescription rates between $11 \%-13 \%$. However, the present study showed $8.3 \%$ (from $80.3 \%$ to $72 \%, \mathrm{p}=0.007$ ) overall reduction in antibiotic prescription rate. Doyne et al. ${ }^{16}$ recently reported that antibiotic use decreased with no adverse effects, after an academic detailing compared with a minimal intervention (handing out written guidelines). Other studies included educational interventions for both parents and physicians had promising results. ${ }^{17-18}$

However, only a few studies assessed the changes with regard to specific diagnoses, as was done in this study. Smabrekke et al. ${ }^{19}$ noted a reduction in antibiotic prescriptions for AOM, from $90 \%$ to $74 \%$, and also a reduction in broad-spectrum antibiotic use, after an educational intervention addressing physicians and parents. Melander et al. ${ }^{20}$ studied the effect of a medical audit on antibiotic prescribing for respiratory tract infection in children and adults. Antibiotic use for AOM dropped from $93 \%$ to $88 \%$. In the present study we achieved much higher rate of reduction in antibiotic prescribing for AOM $\{14.2 \%$ from $\% 9$. to $75.8 \%(\mathrm{p}=0.033)\}$. In comparison with Melander et al. ${ }^{20}$ who reported $17 \%$ reduction in antibiotic prescription for tonsillopharyngitis, our study revealed only $12.2 \%$ (from $78 \%$ to $65.8 \%, \mathrm{p}=0.019)$ reduction in the rate of antibiotic prescription for the same condition. The success in reducing antibiotic prescription in the present study might also be due to encouraging the no antibiotic strategy with watchful waiting principle. This last concept is supported by the findings of Mainous et al. ${ }^{21}$ who showed that close observation without treatment of a first episode of AOM with no risk factors is a safe and cost effective strategy. Again NICE guidelines confirmed that immediate antibiotic use for the four common RTI examined in the present study is only effective when the patient is systemically very unwell, with complications (quinsy, mastoiditis, pneumonia etc.), serious preexisting comorbidities, immune compromised patients or when the patient is above 65 years old. ${ }^{4}$

The higher reduction in antibiotic prescription for AOM compared to tonsillopharyngitis in the present study may be due to many factors including, the pressure of parents or the sick person who used to examine the throat and tonsils by themselves before visiting the 
doctor, the odynophagia that interfere with normal feeding especially among children and many other factors related to the patient, parents or the doctor himself.

In agreement with Akkerman et al. ${ }^{22}$ who did not demonstrate any change in the antibiotic prescription pattern for sinusitis after the intervention with high rate of using second line antibiotics for sinusitis (Cefuroxime and amoxicillin/clavulanate), the present study did not demonstrate improvement in rates of antibiotic prescription between the two study periods in treating both acute sinusitis and bronchitis. On the other hand, the present study demonstrateds an overall improvement in using first line antibiotic when its use was justified $(11.9 \%, \quad \mathrm{P}=0.001)$ with subsequent improvement in selecting antibiotic for both tonsillopharyngitis (17.8\%, $\mathrm{P}=0.004)$ and AOM (8.2\%, $\mathrm{p}=0.004)$. Lack of improvement in using first line antibiotic when treating rhino sinusitis and bronchitis might be due to fear of developing complications like perforation of drum, mastoiditis or pneumonia respectively. The effect of drug company representatives could not be excluded.

The significant improvement in using diagnostic criteria for antibiotic use after the intervention for the 4 studied RTI might reflect the readiness of the participating faculty residents to change their diagnostic skills, the effectiveness of the educational program which stressed on teaching simple diagnostic criteria summarized from international guidelines such as NICE and American family physician.

The main limitation of our study is the lack of a control group. Therefore, the reduction in antibiotic prescribing cannot be attributed solely to our intervention. Recent publications in the medical literature and in the public media have alerted physicians to the dangers of antibiotic overuse and have led to a worldwide decline in prescription for antibiotics mainly among the pediatric population. ${ }^{23}$ Indeed, some studies of the effect of education showed a reduction in antibiotic use also in the control group which did not undergo the intervention. ${ }^{24}$ Also we did not study the outcome of treatment during the two study periods as the manual information system of the family health center does not supply with accurate follow up data to determine the outcome of treatment. Also we did not assess whether different rates of change in antibiotic treatment were associated with these patient, provider, and illness characteristics.

\section{Conclusion:}

Clinical diagnosis of bacterial causes of RTIs and appropriate antibiotic use for these infections can be improved in primary health care settings using a physician based educational program. Further investigation is needed to identify areas that require more attention, such as factors interfering with selection of first line antibiotics when treating respiratory tract infections.

\section{References}

1. Hueston WJ, Mainous AG, 3rd. Acute bronchitis. Am Fam Physician. 1998 Mar 15; 57(6): 1270-6. PMID: 9531910

2. Ranji S, Steinman M, Shojania K. Closing the Quality Gap: A Critical Analysis of Quality Improvement Strategies (Vol. 4: Antibiotic Prescribing Behavior). Technical Review 9 (Prepared by the Stanford University-UCSF Evidence-based Practice Center under Contract No. 290-02-0017). AHRQ Publication No. 04(06)-0051-4. Rockville, MD: Agency for Healthcare Research and Quality; January 2006.

3. Barnett ML, Linder JA. Antibiotic prescribing to adults with sore throat in the United States, 1997-2010. JAMA Intern Med. 2014 Jan; 174(1): 138-40. PMID: 24091806. 
4. Prescribing of antibiotics for selflimiting respiratory tract infections in adults and children in primary care' (NICE clinical guideline 69): available from www.nice.org.uk/ CGo69.

5. Little P (2005) Delayed prescribing of antibiotics for upper respiratory tract infection. BMJ 331: 301-2.

6. Health belief model, available from: http: // www.jblearning.com/ samples/ 0763743836/ chapter\%204.pdf

7. Guidelines for the Use of Antibiotics in Acute Upper Respiratory Tract Infections. Available from: http: // www.aafp.org/ afp/ 2006/ 0915/ p956.html.

8. NATIONAL INSTITUTE FOR HEALTH AND CARE EXCELLENCE Guideline. Sore throat (acute): antimicrobial prescribing https: // www.nice.org.uk/ guidance/ gid-apg 10000/ documents/ draft-guidance.

9. Sinusitis (acute): antimicrobial prescribing. Available from: https: // www.nice.org.uk/ guidance/ ng79/ chapter/ Recommendations\#choiceof-antibiotic.

10. Diagnosis and Treatment of Acute Bronchitis. Available from: http: // www.aafp.org/ afp/ 2010/ 1201/ p1345.html.

11. Trepka MJ, Belongia EA, Chyou PH et al. The effect of a community intervention trial on parental knowledge and awareness of antibiotic resistance and appropriate antibiotic use in children. Pediatrics 2001; 107: e6.

12. Munck AP, Gahrn-Hansen B, SogaardPet al. Long lasting improvement in general practitioners' prescribing of antibiotics by means of medical audit. Scand J Prim Health Care 1999; 17: 18590.

13. Anon. Medical audit in general practice. I: Effect on doctors' clinical behaviour for common childhood conditions. North of England Study of Standards and Performance in General Practice. Br Med J 1992; 304: 1480-4.
14. Melander E, Bjorgell A, Bjorgell P et al. Medical audit changes in physicians' prescribing of antibiotics for respiratory tract infections. Scand J Prim Health Care 1999; 17: 180-4.

15. Belongia EA, Bradley JS, Chyou P et al. A community intervention trial to promote judicious antibiotic use and reduce penicillin-resistant Streptococcus pneumoniae carriage in children. Pediatrics 2001; 108: 575-83.

16. Doyne EO, Alfaro MP, SiegelRMet al. Arandomized controlled trial to change antibiotic prescribing patterns in a community. Arch Pediatr Adolesc Med 2004; 158: 577-83.

17. Bauchner H, Pelton SI, Klein JO. Parents, physicians, and antibiotic use. Pediatrics 1999; 103: 395-401.

18. De Santis G, Harvey KJ, Howard D et al. Improving the quality of antibiotic prescription patterns in general practice: the role of educational intervention. Med J Aust 1994; 160: 502-5.

19. Smabrekke L, Berild D, Giaever A et al. Educational intervention for parents and health care providers leads to reduced antibiotic use in acute otitis media. Scand J Infect Dis 2002; 34: 6579.

20. Melander E, Bjorgell A, Bjorgell P et al. Medical audit changes in physicians' prescribing of antibiotics for respiratory tract infections. Scand J Prim Health Care 1999; 17: 180-4.

21. Mainous AG, III, Hueston WJ, Love MM, Evans ME, Finger R. An evaluation of statewide strategies to reduce antibiotic overuse. Fam Med. 2000; 32: 22-9.

22. Akkerman AE, van der Wouden JC, Kuyvenhoven MM et al. Antibiotic prescribing for respiratory tract infection in Dutch primary care in relation to patient age and clinical entities. $\mathrm{J}$ Antimicrob Chemother 2004; 54: 116-21 23. White K, Barrett PH, Jr, Price D, Maselli J, Gonzales R. Changing clinician behavior: characteristics associated with decreasing antibiotic 
prescribing in ambulatory practice. J Gen Intern Med. 2000; 15(suppl): 154.

24. Lewis D. Computer-based approaches to patient education: a review of the literature. J Am Med Inform Assoc. 1999; 6: 272-82. 
Table 1: Sociodemographic characteristics of the two study periods.

\begin{tabular}{|l|c|c|c|c|}
\hline Parameters & $\begin{array}{c}\text { Pre intervention } \\
(\mathbf{n = 3 7 0})\end{array}$ & $\begin{array}{c}\text { Post intervention } \\
(\mathbf{n = 4 7 5 )}\end{array}$ & $\boldsymbol{t} / \boldsymbol{x}^{2}$ & $\mathbf{p}$-value \\
\hline Age in $\mathrm{y} \pm \mathrm{SD}$ & $33.36 \pm 5.97$ & $33.55 \pm 5.31$ & $\mathrm{t}: 0.489$ & $0.625(\mathrm{NS})$ \\
\hline Female gender, $\mathrm{n}(\%)$ & $177(47.8 \%)$ & $231(48.6 \%)$ & $\mathrm{x}^{2}: 0.026$ & $0.873(\mathrm{NS})$ \\
\hline $\begin{array}{l}\text { Duration of illness }<7 \\
\text { days, } n(\%)\end{array}$ & $148(40 \%)$ & $193(40.6 \%)$ & $\mathrm{x}^{2}: 0.013$ & 0.909 (NS) \\
\hline
\end{tabular}

t- Independent Sample t-test; $x^{2}$ Chi-square test

This table shows no statistically significant difference between pre and post intervention according to demographic data.

Table 2: Frequency of diagnosis of RTIs before and after intervention.

\begin{tabular}{|c|c|c|c|c|c|c|}
\hline \multirow[t]{2}{*}{ Disease } & \multicolumn{2}{|c|}{$\begin{array}{l}\text { Pre intervention } \\
\qquad(\mathbf{n}=\mathbf{3 7 0})\end{array}$} & \multicolumn{2}{|c|}{$\begin{array}{c}\text { Post intervention } \\
\qquad(n=475)\end{array}$} & \multirow[t]{2}{*}{$x^{2}$} & \multirow[t]{2}{*}{$P$ value } \\
\hline & No. & $\%$ & No. & $\%$ & & \\
\hline Tonsillopharyngitis & 150 & 40.5 & 190 & 40.0 & 0.006 & $0.939(\mathrm{NS})$ \\
\hline Acute otitis media & 70 & 18.9 & 95 & 20.0 & 0.098 & $0.754(\mathrm{NS})$ \\
\hline Acute sinusitis & 65 & 17.6 & 92 & 19.4 & 0.334 & $0.563(\mathrm{NS})$ \\
\hline Acute bronchitis & 85 & 23.0 & 98 & 20.6 & 0.572 & $0.449(\mathrm{NS})$ \\
\hline
\end{tabular}

$x^{2}$ Chi-square test

This table shows no statistically significant difference between pre and post intervention according to frequency of RTIs diagnosis. 
Table 3: Rate of antibiotic prescription for RTIs before and after intervention.

\begin{tabular}{|l|c|c|c|c|c|c|}
\hline \multirow{2}{*}{ Diagnosis } & \multicolumn{2}{|c|}{ Pre intervention } & \multicolumn{2}{c|}{ Post intervention } & \multirow{2}{*}{$\boldsymbol{x}^{2}$} & \multirow{2}{*}{ P value } \\
\cline { 2 - 6 } & No. & $\%$ & No. & $\%$ & & \\
\hline Tonsillopharyngitis & $117 / 150$ & 78.0 & $125 / 190$ & 65.8 & 5.502 & $\mathbf{0 . 0 1 9}(\mathbf{S})$ \\
\hline Acute otitis media & $63 / 70$ & 90.0 & $72 / 95$ & 75.8 & 4.551 & $\mathbf{0 . 0 3 3}(\mathbf{S})$ \\
\hline Sinusitis & $45 / 65$ & 69.2 & $63 / 92$ & 68.5 & 0.007 & $0.935(\mathrm{NS})$ \\
\hline Acute bronchitis & $72 / 85$ & 84.7 & $82 / 98$ & 83.7 & 0.027 & 0.869 (NS) \\
\hline All antibiotic prescriptions & $297 / 370$ & 80.3 & $342 / 475$ & 72.0 & 7.331 & $\mathbf{0 . 0 0 7}(\mathbf{S})$ \\
\hline
\end{tabular}

\section{$x^{2}$ Chi-square test}

This table shows statistically significant difference between pre and post intervention groups according to rate of antibiotic prescription in treating tonsillopharyngitis, acute otitis media and overall antibiotic prescriptions.

Table 4: Changes in appropriateness of using diagnostic criteria for antibiotic use in RTI before and after intervention.

\begin{tabular}{|l|c|c|c|c|c|c|}
\hline \multirow{2}{*}{\multicolumn{1}{|c|}{ Diagnosis }} & \multicolumn{2}{c|}{$\begin{array}{c}\text { Before } \\
\text { intervention }\end{array}$} & \multicolumn{2}{c|}{$\begin{array}{c}\text { After } \\
\text { intervention }\end{array}$} & \multirow{2}{*}{$\boldsymbol{x}^{2}$} & \multirow{2}{*}{ P value } \\
\cline { 2 - 5 } & $\mathbf{N}$ & $\mathbf{\%}$ & $\mathbf{N}$ & $\boldsymbol{\%}$ & & \\
\hline Tonsillopharyngitis & $74 / 150$ & 49.3 & $96 / 190$ & 50.5 & 0.012 & $0.912(\mathrm{NS})$ \\
\hline Acute otitis media & $33 / 70$ & 47.1 & $46 / 95$ & 48.4 & 0.018 & 0.893 (NS) \\
\hline Acute rhinosinusitis & $32 / 65$ & 49.2 & $44 / 92$ & 47.8 & 0.012 & 0.913 (NS) \\
\hline Acute bronchitis & $43 / 85$ & 50.6 & $49 / 98$ & 50.0 & 0.005 & $0.946(\mathrm{NS})$ \\
\hline $\begin{array}{l}\text { Overall antibiotic } \\
\text { appropriateness }\end{array}$ & $182 / 370$ & 49.2 & $235 / 475$ & 49.5 & 0.093 & 0.760 (NS) \\
\hline
\end{tabular}

$x^{2}$ Chi-square test

This table shows no statistically significant difference between before and after intervention according to diagnostic criteria for antibiotic. 
Table 5: Changes in appropriate selection of antibiotic for RTIs during the two study periods.

\begin{tabular}{|c|c|c|c|c|c|c|}
\hline \multirow{3}{*}{ Diagnosis } & \multicolumn{4}{|c|}{$\begin{array}{c}\text { Rates of appropriate selection of } \\
\text { antibiotic }\end{array}$} & \multirow[t]{3}{*}{$x^{2}$} & \multirow[t]{3}{*}{ P value } \\
\hline & \multicolumn{2}{|c|}{$\begin{array}{c}\text { Pre } \\
\text { intervention }\end{array}$} & \multicolumn{2}{|c|}{$\begin{array}{l}\text { Post- } \\
\text { intervention }\end{array}$} & & \\
\hline & No. & $\%$ & No. & $\%$ & & \\
\hline Tonsillopharyngitis & $70 / 117$ & 59.8 & $97 / 125$ & 77.6 & 8.138 & $0.004(\mathrm{~S})$ \\
\hline Sinusitis & $30 / 63$ & 47.6 & $43 / 72$ & 59.7 & 1.524 & $0.217(\mathrm{NS})$ \\
\hline Acute otitis media & $31 / 45$ & 68.9 & $58 / 63$ & 92.1 & 8.221 & $0.004(\mathrm{~S})$ \\
\hline Acute bronchitis & $43 / 72$ & 59.7 & $48 / 82$ & 58.5 & 0.023 & $0.880(\mathrm{NS})$ \\
\hline $\begin{array}{l}\text { Overall appropriate } \\
\text { selection }\end{array}$ & $174 / 297$ & 58.6 & $246 / 342$ & 71.9 & 11.897 & $<0.001(\mathrm{HS})$ \\
\hline
\end{tabular}

$x^{2}$ Chi-square test

This table shows statistically significant changes in appropriate selection of antibiotic for RTIs during the two study periods for both tonsillopharyngitis and acute otitis media. 